\title{
Protein-based nanotechnology: Antibody conjugated with photosensitizer in targeted anticancer photoimmunotherapy
}

\author{
JERZY JANKUN ${ }^{1-3}$ \\ ${ }^{1}$ Urology Research Center, Department of Urology, The University of Toledo - Health Science Campus, 3000 Arlington Ave., \\ Toledo, OH 43614, USA; ${ }^{2}$ Department of Clinical Nutrition, Medical University of Gdańsk, Dębinki 7, \\ 80-211 Gdańsk; ${ }^{3}$ Protein Research Chair, Biochemistry Department, King Saud University, Riyadh, Saudi Arabia
}

Received April 13, 2011; Accepted May 26, 2011

DOI: $10.3892 /$ ijo.2011.1110

\begin{abstract}
Photodynamic therapy (PDT) is a minimally invasive cancer therapy that depends on the buildup of a photosensitizing drug within targeted tissue. The photosensitizer is subsequently activated by light of a specific wavelength, resulting in destruction of the targeted tissue by free radicals or singlet oxygen. Successful treatment requires delivery of critical amounts of drug into the cancerous tissue. This frequently demands high doses of the drug in the circulatory system that could lead to side effects in normal daylight due to accumulation of photodrug in normal tissue. To reduce drug load we explored the possibility of targeting cancer with antibody conjugated with photosensitizer. As a model we used LnCAP human prostate cancer cells targeted by antibody (against prostate-specific membrane antigen) which was conjugated with hematoporphyrin (HP). Our results show clearly that $\mathrm{mAb} / \mathrm{HP}$ conjugates can deliver HP to the tumor cells which would result in considerably less HP in the circulation and, therefore, lower the delivery of HP to normal tissue, resulting in fewer side effects.
\end{abstract}

\section{Introduction}

Photodynamic therapy (PDT) is an emerging, minimally invasive treatment that can be used in many human diseases (1-3). PDT relies on the accumulation of a photosensitizing drug within the targeted tissue followed by activation of photosensitizer by light and the active drug destroys the treated tissue. During PDT free radicals or singlet oxygen are generated and these are responsible for phototoxicity leading to cell death $(1,3,4)$. A variety of photochemicals has been used in cancer treatment, and management of certain cancers has received considerable amount of attention (5-7). It has been recognized by many groups that numerous photosensitizers have a selective affinity for malignant cells; however it has also been shown to have toxic effects on

Correspondence to: Dr Jerzy Jankun, Urology Research Center, Department of Urology, The University of Toledo - Health Science Campus, 3000 Arlington Ave., Toledo, OH 43614, USA

E-mail: jerzy.jankun@utoledo.edu

Key words: phototherapy, LnCAP, CYT-351, hematoporphyrin normal cells. For example patients treated with effective levels of photochemicals experience side effects in normal daylight due to accumulation of photodrug in normal tissue $(5,6,8-10)$. We have investigated the possibility that conjugate of prostate specific membrane antigen (PSMA) antibody (CYT-351) with photosensitizer would focus more selectively the photochemical onto the prostate cancer cell to be activated by light to destroy the target cell. We have investigated two methods of conjugation of hematoporphyrin (HP) with antibody. One approach conjugates randomly HP to different part of the mAb molecule, while the other links HP at the sites of glycosylation, which are primarily in the $\mathrm{Fc}$ region, far from the antigen binding site. Our results show clearly that $\mathrm{mAb} / \mathrm{HP}$ conjugates can deliver HP to the tumor cells which would result in considerably less HP in the circulation and therefore lower the delivery of HP to normal tissue resulting in fewer side effects. We have observed no differences between different methods of conjugation of $\mathrm{mAb}$ and PDT effectiveness of these constructs.

\section{Materials and methods}

CYT-351 antibody against prostate-specific membrane antigen was purchased from Cytogen Princeton, NJ, USA.

Conjugation of CYT-351 with hematoporphyrin. Direct conjugation of hematoporphyrin (HP) and CYT-351 was done as described by Mew et al $(5,6)$. All reactions were carried out in room temperature and in low light, unless stated differently. Briefly, $60 \mu \mathrm{M}$ of HP were dissolved with $3 \mathrm{mM}$ of anhydrous 1-ethyl-3-(dimethyl aminopropyl) carbodiimide (EDC) from Pierce (Rockford, IL, USA) and in $6 \mathrm{ml}$ of anhydrous dimethyl sulfoxide (DMSO). Then mixture was stirred for $12 \mathrm{~h}$, and stored at room temperature not more than 10 days. EDC is a zero-length cross linking instrument coupling carboxyl groups to primary amines (Fig. 1). An aliquot of $175 \mu$ l of HP-EDC was added to $3.5 \mathrm{ml}$ of antibody $(1 \mathrm{mg} / \mathrm{ml})$ and mixed for $1 \mathrm{~min}$ in light protected vessel. Conjugated antibody was separated from substrates on PD-10 column from Amersham Biosciences Corp. (NJ, USA). PD-10 column was equilibrated with $25 \mathrm{ml}$ of PBS and $2.5 \mathrm{ml}$ of reacting mixture was applied on top of column, the flow-through was discarded. Next $3.5 \mathrm{ml}$ buffer was added and flow-through containing conjugated antibody was collected. 

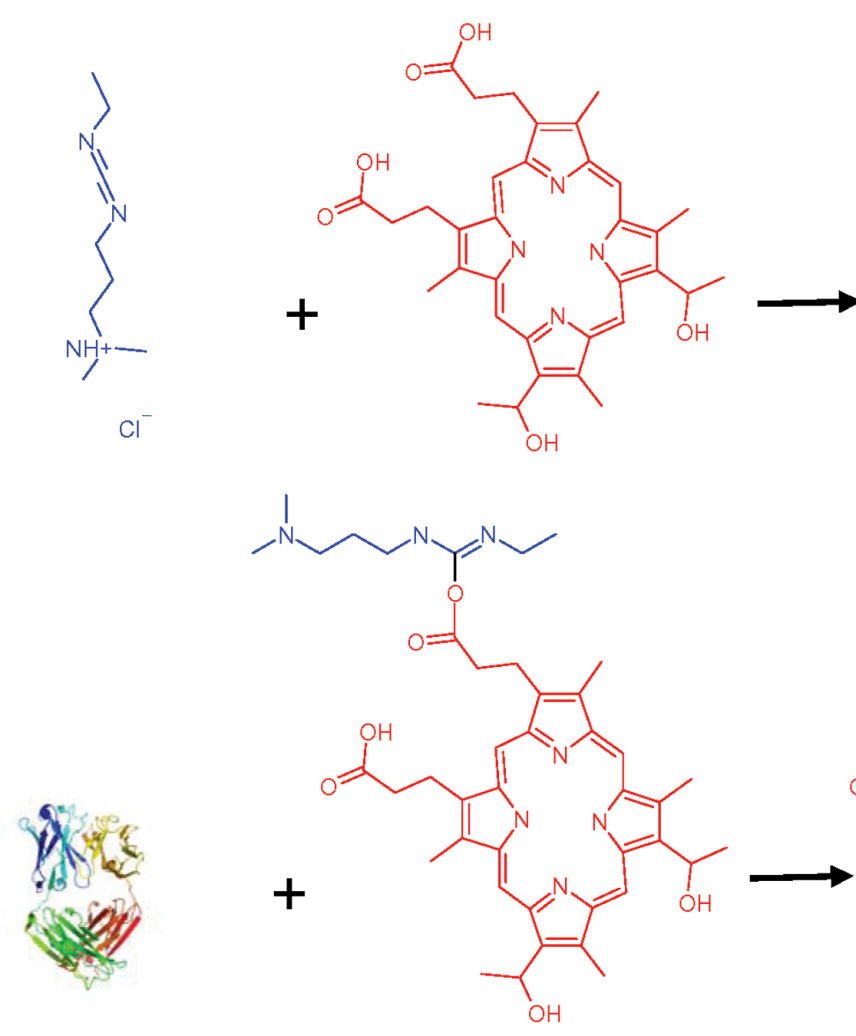
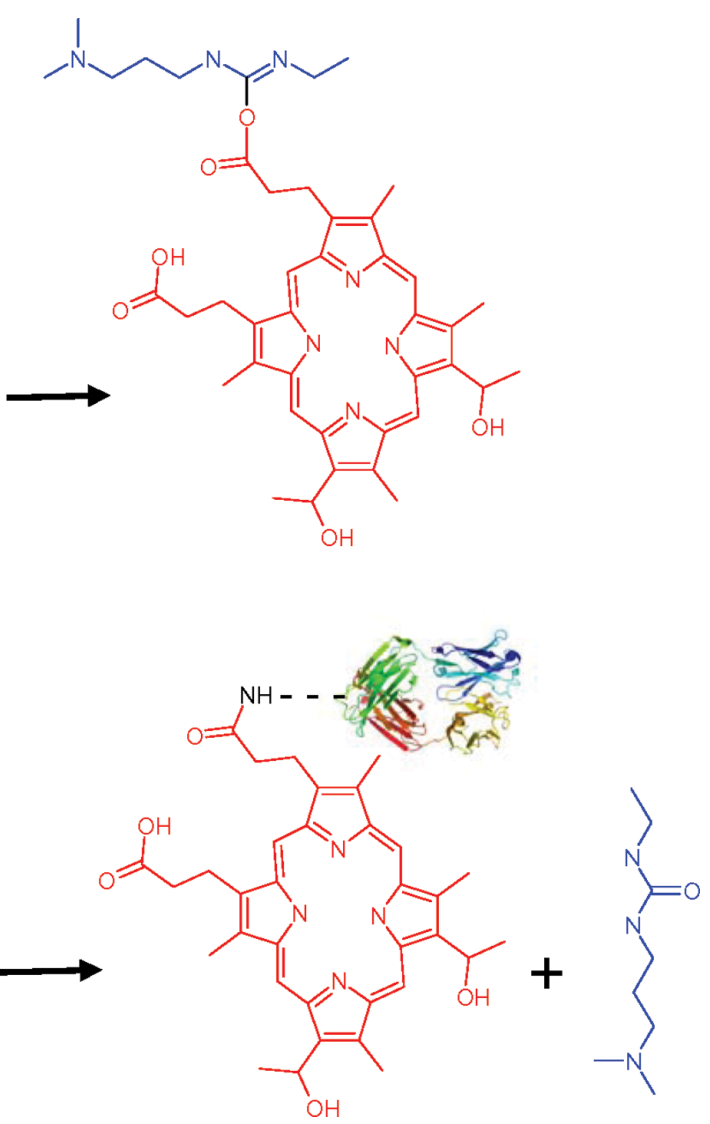

Figure 1. Direct conjugation of hematoporphyrin (HP, shown in red) and antibody (ribbon model colored as rainbow) using 1-ethyl-3-(dimethyl aminopropyl) carbodiimide (EDC, shown in blue) as a zero length linker.

Conjugation of hematoporphyrin and CYT-351 Ox by biotin avidin bridge. We used EZ-Link Hydrazide-LC-Biotin of hydrazide-activated biotin that enables biotinylation of glycoproteins having oxidizable sugars or aldehydes (Pierce) following the manufacturer's instructions. Weak oxidation of antibodies with sodium periodate $\left(\mathrm{NaIO}_{4}\right)$ forms reactive aldehydes on the carbohydrate moieties of the $\mathrm{Fc}$ chain to be modified by hydrazides (Fig. 2). This method is beneficial for labeling antibodies since biotinylation takes place only at the sites of glycosylation, which are primarily in the $\mathrm{Fc}$ region, far from the antigen binding site (11-13). Briefly, $1 \mathrm{ml}$ of cold sodium periodate solution $(20 \mathrm{mM}$ sodium periodate in $0.1 \mathrm{M}$ sodium acetate buffer, $\mathrm{pH}$ 5.5) was added to $1 \mathrm{ml}$ of cold CYT-351 antibody $(1 \mathrm{mg} / \mathrm{ml})$ mixed and incubated for $30 \mathrm{~min}$ at $4^{\circ} \mathrm{C}$. Excess of periodate was removed through a desalting column that previously has been equilibrated with coupling buffer $(0.1 \mathrm{M}$ sodium phosphate, $0.15 \mathrm{M} \mathrm{NaCl}$, $\mathrm{pH}$ 7.2). Next 1 part of biotin hydrazide solution $(50 \mathrm{mM})$ was added to 9 parts of oxidized and buffer-exchanged antibody and mix for $2 \mathrm{~h}$. The biotinylated CYT-351 was separated from nonreacted material by gel filtration (desalting column). Conjugation of hematoporphyrin with avidin (NeutrAvidin Protein (Pierce) was done as described for CYT-351. Biotinylated antibody and HP conjugated avidin where combined 1:1 ratio and mixed for $1 \mathrm{~h}$. Next mixture buffer was adjusted to the composition of the binding buffer ( $20 \mathrm{mM}$ sodium phosphate, $\mathrm{pH} 7.0$ ) by buffer exchange using PD-10 desalting column. Conjugated antibody was loaded onto HiTrap Protein G column, Pharmacia Biotech Inc. (Piscataway, NJ, USA). Column was washed with $10 \mathrm{ml}$ of binding buffer and antibody was eluted with $5 \mathrm{ml}$ of elution buffer (0.1 M glycine- $\mathrm{HCl}, \mathrm{pH}$ 2.7). The purified fractions were immediately buffer-exchanged using PBS and frozen until used.

Concentration measurement. Protein and HP concentration were measured spectroscopically at $280 \mathrm{~nm}$ for $\mathrm{mAb}$ and at $375 \mathrm{~nm}$ for HP.

Gel electrophoresis. Electrophoresis of HP conjugated CYT-351 antibody was performed at room temperature using $10 \%$ SDS-polyacrylamide gels under non-reducing conditions. Gels were stained with Coomassie brilliant blue, Invitrogen (Grand Island, NY). Gels were illuminated with visible and UV light and photographed.

Prostate cancer cells. LnCAP human prostate cancer cells were purchased from American Type Culture Collection (ATCC), (Manassas, VA, USA). The cells were propagated in RPMI-1640 medium, Sigma Chemical Co. (St. Louis, MO), and supplemented with 10\% fetal bovine serum, Hyclone Laboratories (Logan, UT, USA), penicillin and streptomycin.

PDT treatment of prostate cancer cells; LnCAP. Cells were incubated with HP $(48,24,12,6,3 \mu \mathrm{g} / \mathrm{ml})$ or CYT-351/HP and CYT351 Ox/HP (10, 5, $2.51 .2,0.6 \mu \mathrm{g} / \mathrm{ml}$ of HP conjugated to antibody) for $180 \mathrm{~min}$ in 24 -wells cell culture dish. Next media was removed and washed three times with PBS. Finally $0.5 \mathrm{ml}$ of PBS was added and cells were irradiated to deliver $0.21 \mathrm{~J} / \mathrm{cm}$ of red light (ruby red filter from Kodak - >610 nm). 

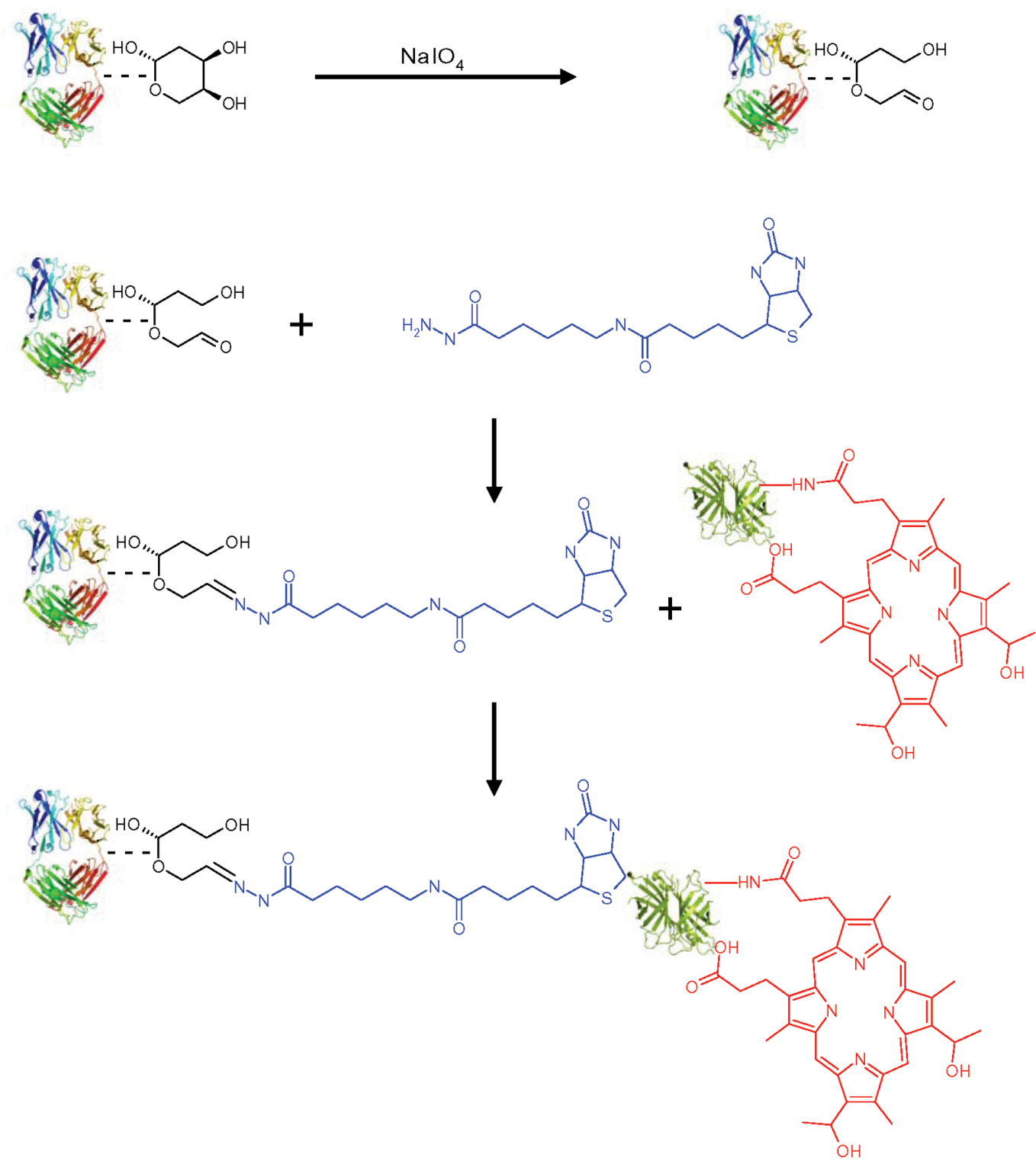

Figure 2. Conjugation of hematoporphyrin (HP, shown in red) conjugated to avidin (ribbon model, green color) and antibody (ribbon model colored as rainbow) using Hydrazide-LC-Biotin linker (EDC, shown in blue).

\section{$1 \times \quad 2 \times \quad 0.5 \times$}

\section{Coomassie Brilliant Blue stain}

\section{Fluorescence of hematoporphyrin conjugated with CYT-351}

Figure 3. Coomassie stained CYT-351/HP conjugate (upper picture), the same antibody conjugate illuminated by UV light (lower picture).

Total emitted power was verified before and after PDT photoirradiation using an integrating sphere-based power meter (Labsphere, Hanover, NH, USA). After light treatment, cells were trypsinized and resuspended in $5 \mathrm{ml}$ of media and seeded in P100 dish for clonal assay.

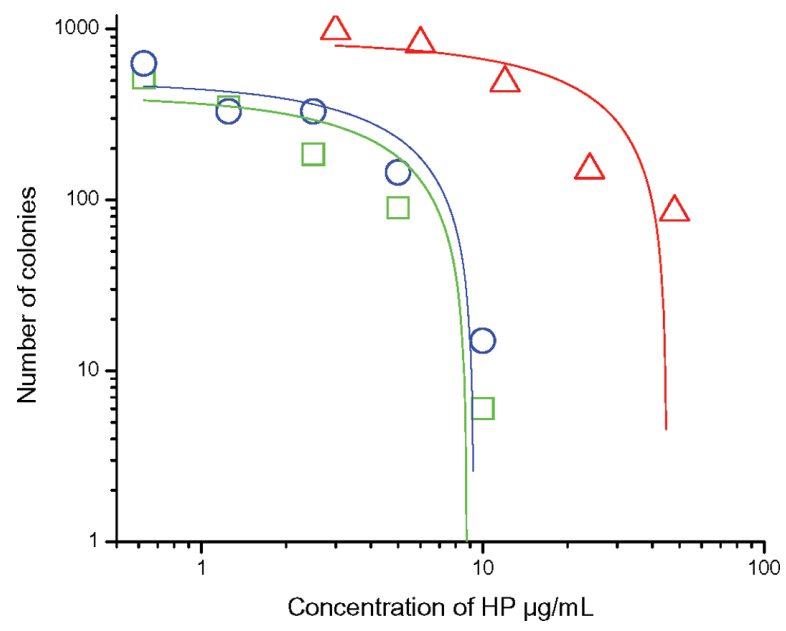

Figure 4. LnCAP human prostate cancer cells treated with: CYT-351 Ox/HP (green squares); CYT-351/HP (blue circles); HP (red triangles). Concentration of HP conjugated to antibodies was equal to: $10,5,2.51 .2,0.6 \mu \mathrm{g} / \mathrm{ml}$ and non-conjugated HP was equal to: $48,24,12,6,3 \mu \mathrm{g} / \mathrm{ml}$. 


\section{Results and Discussion}

Prostate specific membrane antigen is a cell-surface glycoprotein predominantly found in prostate tissue and overexpressed on prostate tumor cells. Expression levels increase as disease progress, and highest levels are observed in metastatic disease. Furthermore, PSMA has also been detected in the neovasculature of a variety of non-prostatic solid malignancies (14). Therefore, PSMA as a biomarker and target for the delivery of therapeutic agents attracted considerable attention in cancer therapy. We chose antibody CYT-351 against PSMA for targeted delivery of PDT agent.

For targeted PDT to be successful, critical amounts of photosensitizer must be conjugated to the MAb without altering its activity. Few methods of conjugation can be used to conjugate the antibody and drug. One of the most frequently used conjugation methods involves the use of a zero-length crosslinker (Fig. 1), EDC for the formation of amide bonds between carboxyl groups and primary amines of antibody (predominantly lysine). However, in this coupling method, there is a risk that the antigen binding sites at the Fab region of antibody are blocked by the nonselective formation of HP/antibody bonds (1,2,15-17). Thus, we chose the second, method of conjugation into the carbohydrate moieties of the $\mathrm{Fc}$ chain of the antibody, far from the active site. We use Hydrazide-LC-Biotin linker with spacer of $23.7 \AA$ (Fig. 2). Disadvantage of this method over EDC conjugation is the lengthy and multistep procedure $(12,13)$. Both methods yielded CYT-351/HP and CYT-351 Ox/HP conjugates. As seen in Fig. 3, stained PAGE gel showed distinct bands of HP conjugated CYT-351 antibody. Furthermore, gel illuminated with UV light showed red colored bands of antibody characteristic to HP fluorescence; nonconjugated antibody does not produce any fluorescence.

As shown in Fig. 4 significant cancer cell killing was observed for cells incubated with CYT-351/HP conjugated and non-thermal light treatment starting with concentration of $1.25 \mu \mathrm{g} / \mathrm{ml}$ of HP conjugated to antibodies. Both forms of antibody/HP conjugates had similar cancer cell killing potency indicating that conjugation did not affect the binding site of the antibody but delivered therapeutic amount of HP into cancer cells. Similar cancer cell ablation effect can be observed for unconjugated HP but at concentration of $\sim 24 \mu \mathrm{g} / \mathrm{ml}$. Above indicates improved targeting delivery and accumulation of HP in cancer cells by CYT-351 antibodies over HP alone. Targeting the tumor cells with antibodies/HP conjugates would result in considerably less HP in the circulation and consequently lower the general skin sensitivity of patients to light. That was the most important contraindication observed in human patient trials (18-22). Additional benefits of PDT with CYT-351 conjugates include damage to newly formed cancer angiogenic vessels which can lead to increased vascular permeability that could greatly improve PDT's therapeutic margin (23).

CYT-351 was developed in the 1980s and is successfully used in therapy, diagnosis by conjugating CYT-351 with radioactive elements (24-27). Recently, an interesting and similar to our approach to target PSMA with bioconjugate of photosensitizer and inhibitor of PSMA was presented by Liu et al where PSMA targeting small-molecule of this conjugate served as a delivery vehicle for PDT of prostate cancer. They found that PSMA ${ }^{+}$cells treated with PS-inhibitor/photosen- sitizer conjugate and subsequent light treatment underwent apoptosis while PMSA- cells did not (28). This work confirms our findings that PSMA can be used as a target in for PDT immunotherapy.

Our results clearly demonstrate the potential use of CYT-351/ HP conjugates for killing of selectively targeted cells using photo-activation the HP. However, the possible phototherapy might require additional work most likely including optimization of dose, ratio of $\mathrm{mAb}$ to photosensitizer or even humanization of antibodies to reduce immune response.

\section{Acknowledgments}

This work was supported by grant from: Stranahan Endowment Fund for Oncological Research.

\section{References}

1. Allison RR, Mota HC, Bagnato VS and Sibata CH: Bio-nanotechnology and photodynamic therapy - state of the art review. Photodiagnosis Photodyn Ther 5: 19-28, 2008.

2. Jankun J,Keck RW, Skrzypczak-Jankun E, Lilge L and Selman SH: Diverse optical characteristic of the prostate and light delivery system: implications for computer modelling of prostatic photodynamic therapy. BJU Int 95: 1237-1244, 2005.

3. Mitton D and Ackroyd R: A brief overview of photodynamic therapy in Europe. Photodiagnosis Photodyn Ther 5: 103-111, 2008.

4. Jankun J, Lilge L, Douplik A, et al: Optical characteristics of the canine prostate at $665 \mathrm{~nm}$ sensitized with tin etiopurpurin dichloride: need for real-time monitoring of photodynamic therapy. $\mathbf{J}$ Urol 172: 739-743, 2004

5. Mew D, Lum V, Wat CK, et al: Ability of specific monoclonal antibodies and conventional antisera conjugated to hematoporphyrin to label and kill selected cell lines subsequent to light activation. Cancer Res 45: 4380-4386, 1985.

6. Mew D, Wat CK, Towers GH and Levy JG: Photoimmunotherapy: treatment of animal tumors with tumor-specific monoclonal antibody-hematoporphyrin conjugates. J Immunol 130: 1473-1477, 1983.

7. Novichenko NL, Mamchur AA, Lisniak IO and Gamaliya MF: Study of photodynamic efficiency of the hematoporphyrin conjugated with antibody to VEGF in mouse Lewis carcinoma. Exp Oncol 30: 315-318, 2008.

8. Allen TM and Cullis PR: Drug delivery systems: entering the mainstream. Science 303: 1818-1822, 2004

9. Stalteri MA, Mather SJ, Belinka BA, Coughlin DJ, Chengazi VU and Britton KE: Site-specific conjugation and labelling of prostate antibody 7E11C5.3 (CYT-351) with technetium-99m. Eur J Nucl Med 24: 651-654, 1997.

10. Van Dongen GA, Visser GW and Vrouenraets MB: Photosensitizerantibody conjugates for detection and therapy of cancer. Adv Drug Deliv Rev 56: 31-52, 2004

11. Novick S, Quastel MR, Marcus S, et al: Linkage of boronated polylysine to glycoside moieties of polyclonal antibody; boronated antibodies as potential delivery agents for neutron capture therapy. Nucl Med Biol 29: 159-167, 2002.

12. O'Shannessy DJ, Dobersen MJ and Quarles RH: A novel procedure for labeling immunoglobulins by conjugation to oligosaccharide moieties. Immunol Lett 8: 273-277, 1984.

13. O'Shannessy DJ and Quarles RH: Specific conjugation reactions of the oligosaccharide moieties of immunoglobulins. J Appl Biochem 7: 347-355, 1985.

14. Liu T, Wu LY and Berkman CE: Prostate-specific membrane antigen-targeted photodynamic therapy induces rapid cytoskeletal disruption. Cancer Lett 296: 106-112, 2010.

15. Kwitniewski M, Juzeniene A, Glosnicka R and Moan J: Immunotherapy: a way to improve the therapeutic outcome of photodynamic therapy? Photochem Photobiol Sci 7: 1011-1017, 2008.

16. Milgrom LR: Towards recombinant antibody-fragment targeted photodynamic therapy. Sci Prog 91: 241-263, 2008.

17. Nowak-Sliwinska P, van Beijnum JR, van Berkel M, van den Bergh $\mathrm{H}$ and Griffioen AW: Vascular regrowth following photodynamic therapy in the chicken embryo chorioallantoic membrane. Angiogenesis 13: 281-292, 2010. 
18. Bellnier DA, Greco WR, Loewen GM, Nava H, Oseroff AR and Dougherty TJ: Clinical pharmacokinetics of the PDT photosensitizers porfimer sodium (Photofrin), 2-[1-hexyloxyethyl]-2-devinyl pyropheophorbide-a (Photochlor) and 5-ALA-induced protoporphyrin IX. Lasers Surg Med 38: 439-444, 2006.

19. Brasseur N, Ouellet R, Lewis K, Potter WR and van Lier JE: Photodynamic activities and skin photosensitivity of the bis (dimethylthexylsiloxy)silicon 2,3-naphthalocyanine in mice. Photochem Photobiol 62: 1058-1065, 1995.

20. Kostron H: Photodynamic diagnosis and therapy and the brain. Methods Mol Biol 635: 261-280, 2010

21. Kostron H, Obwegeser A and Jakober R: Photodynamic therapy in neurosurgery: a review. J Photochem Photobiol B 36: 157-168, 1996.

22. Roberts WG, Smith KM, McCullough JL and Berns MW: Skin photosensitivity and photodestruction of several potential photodynamic sensitizers. Photochem Photobiol 49: 431-438, 1989.

23. Hornick JL, Khawli LA, Hu P, Sharifi J, Khanna C and Epstein AL: Pretreatment with a monoclonal antibody/interleukin-2 fusion protein directed against DNA enhances the delivery of therapeutic molecules to solid tumors. Clin Cancer Res 5: 51-60, 1999.
24. Chang SS: Overview of prostate-specific membrane antigen. Rev Urol 6 (Suppl 10): S13-S18, 2004.

25. Horoszewicz JS, Kawinski E and Murphy GP: Monoclonal antibodies to a new antigenic marker in epithelial prostatic cells and serum of prostatic cancer patients. Anticancer Res 7: 927-935, 1987.

26. Troyer JK, Feng Q, Beckett ML and Wright GL Jr: Biochemical characterization and mapping of the 7E11-C5.3 epitope of the prostate-specific membrane antigen. Urol Oncol 1: 29-37, 1995.

27. Vallabhajosula S, Smith-Jones PM, Navarro V, Goldsmith SJ and Bander NH: Radioimmunotherapy of prostate cancer in human xenografts using monoclonal antibodies specific to prostate specific membrane antigen (PSMA): studies in nude mice. Prostate 58: 145-155, 2004.

28. Liu T, Wu LY, Choi JK and Berkman CE: In vitro targeted photodynamic therapy with a pyropheophorbide-a conjugated inhibitor of prostate-specific membrane antigen. Prostate 69: 585-594, 2009. 